\title{
Synthesis and characterization of PVA/Starch/CMC composite films reinforced with walnut (Juglans regia L.) shell flour
}

\author{
Kapil Gulati ${ }^{1} \cdot$ Sohan Lal ${ }^{1} \cdot$ Sanjiv Arora ${ }^{1}$
}

(c) Springer Nature Switzerland AG 2019

\begin{abstract}
Polyvinyl alcohol/Starch/Carboxymethyl cellulose (PSC) composite films were synthesized by solvent casting method using glycerol as plasticizer and citric acid as cross linking agent. The effect of different loadings of carboxymethyl cellulose (CMC) on thermal and tensile properties of PVA/Starch (PS) composites was investigated. The increasing concentration of CMC enhanced the thermal stability of PS composite films. PSC film at an optimum level of CMC showed the maximum tensile strength $(36.56 \pm 1.54 \mathrm{MPa})$ and was further chosen to analyze the effect of walnut shell flour (WSF) addition. PSC films reinforced with different amounts of WSF were analyzed by thermogravimetric analysis, UV absorption spectra, tensile testing, water absorption study and soil burial degradability test. The reinforcement of WSF showed a remarkable improvement in thermal stability and water resistant property of the films. Addition of WSF in PSC films reduced the degradability of films, with maximum percentage of weight loss obtained with $2 \%$ loading. Further, the tensile strength was found to be improved up to $6 \%$ level $(41.09 \pm 0.71 \mathrm{MPa})$. ANOVA of the tensile data recognized the considerable differences between the mean tensile strength from one composition to another $(p<0.05)$.
\end{abstract}

Keywords Starch · Carboxymethyl cellulose $\cdot$ Thermal $\cdot$ Tensile $\cdot$ Walnut

\section{Introduction}

Biodegradable polymeric materials are commendable solution to the menace of solid waste resulting from synthetic polymers $[1,2]$. These synthetic polymers are needed to be replaced by environmentally friendly polymeric materials classified into degradable synthetic and renewable natural polymers [3]. Among these, starch (S) has been used as the most favourable material due to its low price and biodegradable nature [4]. The films completely composed of starch are however rigid, hydrophilic and lacking in strength [5-7]. The possible way to mitigate this problem is by incorporating starch with a stronger support base. Among the existing synthesized polymers, Poly (vinyl alcohol) (PVA) possesses many useful properties such as biodegradability and mechanical strength [8, 9]. Addition of PVA undoubtedly improves the strength, flexibility and is one of the best options to blend with starch in terms of biodegradability [10-12]. Due to high hydrophilic nature and poor compatibility [13] between starch and PVA; these PS films has some constraints. Further, these PS films do not show significant mechanical properties and lacks in water resistance [14]. Addition of plasticizers such as glycerol, sorbitol or ethylene glycol can be the solution to improve its flexibility, but decreases the tensile strength. To improve its tensile properties addition of some non toxic additives/cross linking agents such as citric acid (CA) [15], boric acid [16] and glutaraldehyde [17] etc. have been employed. Citric acid with mono hydroxyl and three carboxyl groups is a natural organic acid which makes its use as cross linking agent. Due to its multi carboxylic structure esterification reaction could take place between the carboxyl groups of CA and hydroxyl groups of PVA and/or starch. The PS films were synthesized by solvent casting method in the presence of glycerol and citric acid [14]. Blending [18] or laminating [19] with other

\footnotetext{
Sanjiv Arora, sarora@kuk.ac.in | 'Department of Chemistry, Kurukshetra University, Kurukshetra, Haryana 136119, India.
} 
polysaccharide materials is helpful in improving the overall product quality. Cellulose based compounds are widely used for improving the overall quality of the composite films. Carboxy methyl cellulose (CMC) having high viscosity and non toxicity can be a better option for providing stability to the PS films [20] and also providing biodegradability [21]. Corn starch based films were synthesized using citric acid and CMC [22]. The use of lignocellulosic materials as reinforcement has also increased because of their great affinity. M. Guimarels [23] has synthesized PS based nanocomposites reinforced with bamboo fibers. The use of natural fibers such as bamboo, jute, coir fiber and some nutshell such as coconut shell, walnut shell, almond shell powders as reinforcement is preferred because of their easy availability and biodegradability [24-26]. Walnut shell constitutes $67 \%$ of total weight of nut and around 1.5 million tons of walnut shell is discarded every year [27]. This huge amount of waste has no industrial usage and generally left behind or burned in stove during winter which creates environmental issues. Walnut shell being a lignocellulosic agricultural waste offers notable advantages for polymer composites to make its use as reinforcing filler. Walnut shell flour (WSF) is preferred also due to the lower amounts of hygroscopic (cellulose and hemicellulose) and higher amounts of hydroscopic components (lignin and extractives) as shown Table 1. The larger amount of lignin is responsible for providing the significant mechanical strength of shells [28]. For thermoplastic composites, walnut shell flour (WSF) as filler is significant in various outdoor applications. Walnut shell thus can be used as a substitute of wood in the manufacturing of wood based panels such as particleboards, window frames etc. [29] Guru et al. [30] synthesized the polymer composite particleboards using walnut shell. Based on the findings obtained from the results of Ayrilmis et al. [31], it was observed that reinforcement of WSF improved the

Table 1 Chemical composition of walnut shell flour [31]

\begin{tabular}{lllll}
\hline Composition & Cellulose & Lignin & Holocellulose & Ash \\
\hline Value (\%) & 26.51 & 49.18 & 47.78 & 2.13 \\
\hline
\end{tabular}

tensile and flexural modulus of polypropylene (PP) matrix based composites.

No specific studies have been reported dealing the combined effect of CA and CMC on the PVA/Starch composite films. The present work includes the influence of CMC addition on the thermal and tensile properties of PVA/Starch films synthesized by the method adopted by Zhou et al. [14] The effect of walnut shell flour as reinforcement in the above obtained films was further explored.

\section{Materials and method}

\subsection{Materials}

Poly (vinyl alcohol) (PVA) $\left(\mathrm{M}_{\mathrm{w}}=85,000-1,24,000\right)$ and Corn starch was supplied by SDFCL ( $\mathrm{d}$ d fine-chem limited). Glycerol was obtained from RFCL, Carboxymethyl cellulose was purchased from LOBA CHEMIE. Walnut shells obtained from producer were cleaned of impurities and ground to flour. Particles passing through 18 mesh sieve were used as reinforcement.

\subsection{Method}

PVA/Starch/CMC (PSC) film preparation PS films plasticized with $20 \%$ glycerol and $5 \%$ citric acid were prepared by solvent casting method [14]. CMC solution $(0,5,10,15$ and $20 \%$, W/W PVA/Starch) was solubilized in $75 \mathrm{ml}$ of distilled water at $80^{\circ} \mathrm{C}$ for $10 \mathrm{~min}$ (Table 2). CMC and PS solutions were mixed together and magnetically stirred for $2 \mathrm{~h}$ to form a homogeneous gel-like solution. The solution was poured into glass dishes and dried in vacuum oven at $60{ }^{\circ} \mathrm{C}$ to cast the films. The influence of CMC concentrations on the thermal and mechanical properties of PS films was analyzed. There was a slight increase in the thermal stability of obtained films containing different amount of CMC. The film containing 10\% CMC with moderate thermal stability and tensile strength $(36.56 \pm 1.54 \mathrm{MPa})$ was further chosen for analyzing the effect of walnut shell flour (WSF) loading.

PSC/Walnut (PSCW) film preparation:
Table 2 Composition of different CMC modified composites

\begin{tabular}{lllll}
\hline Sample index & PVA/Starch & $\begin{array}{l}\text { Glycerol (wt\% of dry } \\
\text { weight) }\end{array}$ & $\begin{array}{l}\text { Citric acid(g) (wt\% of } \\
\text { dry weight) }\end{array}$ & $\begin{array}{l}\text { CMC (wt\% } \\
\text { of dry } \\
\text { weight) }\end{array}$ \\
\hline PSC0 & $3: 1$ & 20 & 5 & - \\
PSC5 & $3: 1$ & 20 & 5 & 5 \\
PSC10 & $3: 1$ & 20 & 5 & 10 \\
PSC15 & $3: 1$ & 20 & 5 & 15 \\
PSC20 & $3: 1$ & 20 & 5 & 20 \\
\hline
\end{tabular}


PSC10 film containing 10\% CMC was chosen for further studies and reinforced with different amount of WSF (Table 3). The effect of this reinforcement on different properties of the films was further investigated. The thickness of obtained films was maintained to $0.25 \mathrm{~mm}$.

\section{Characterizations}

\subsection{FTIR spectroscopy}

FTIR spectra recorded on a MB-3000 ABB spectrophotometer in transmission mode over the frequency range of $4000-600 \mathrm{~cm}^{-1}$, was used for the identification of specific functional groups in the composite films.

\subsection{Thermogravimetric analysis (TGA)}

TGA of the samples was performed on STAH instrument at the heating rate of $10{ }^{\circ} \mathrm{C} \mathrm{min}^{-1}$ in an inert nitrogen atmosphere by taking dry alumina $\left(\mathrm{a}-\mathrm{Al}_{2} \mathrm{O}_{3}\right)$ as a reference. Samples were placed in ceramic pans and about $8-10 \mathrm{mg}$ of sample was used for thermal analysis.

\subsection{Mechanical property}

Mechanical properties of the films like Ultimate tensile strength (UTS), elongation at break and Young's modulus were studied on Universal Testing Machine (UTM) Model AG-IS Shimadzu. The films samples were placed in a closed container with relative humidity of $50 \%$ before testing. The test samples were in accordance with ASTM D-882 standards maintaining the gauge length of $50 \mathrm{~mm}$ and cross head speed of $10 \mathrm{~mm} \mathrm{~min}^{-1}$. The samples were tested in triplicate for each category for tensile analysis and an average value is reported.

\subsection{Swelling study}

Prior to testing, the films were stored at $104{ }^{\circ} \mathrm{C}$ for $24 \mathrm{~h}$. The swelling behaviour [15] of the films was determined by immersing the dried and accurately weighed films $\left(w_{0}\right)$ in $20 \mathrm{ml}$ distilled water at $25^{\circ} \mathrm{C}$. After $24 \mathrm{~h}$ the films were removed, wiped and weighed $\left(w_{t}\right)$. The degree of swelling (DS) was calculated from the following equation:

$\mathrm{DS}=\frac{\mathrm{w}_{\mathrm{t}}-\mathrm{w}_{0}}{\mathrm{w}_{\mathrm{o}}} \times 100$

where $w_{t}$ is the weight of immersed films obtained after $24 \mathrm{~h}$ and $\mathrm{w}_{\mathrm{o}}$ is the initial weight of vacuum dried films (in gram). The results have been reported as the average values corresponding to three different samples of each category.

\subsection{Light absorbance property}

Light absorbance of the films against UV light was recorded on the UV-Vis spectrophotometer (Model Shimadzu Double Beam Double Monochromator (UV-2550)) test cell. The spectrum was recorded in wavelength range between 200 and $800 \mathrm{~nm}$. An average value was reported for each sample.

\subsection{Soil degradability test}

In order to determine the biodegradability, films were fully buried in the soil containing $6 \mathrm{~g}$ urea per $\mathrm{kg}$, kept moist to activate the growth of microorganisms. The weight loss of the samples was determined at the regular time interval of 15 days for duration of 2 months. An average percentage weight change was obtained for three independent samples by using the following equation:

$\%$ degradation of composite films $=\frac{\mathrm{w}_{\mathrm{i}}-\mathrm{w}_{\mathrm{t}}}{\mathrm{w}_{\mathrm{i}}} \times 100$

where $w_{i}$ is the initial weight of dried film and $w_{t}$ is the dried weight of film (in gram) after the soil burial at the time $t$.
Table 3 Composition of walnut shell flour reinforced composites

\begin{tabular}{llllll}
\hline Sample index & PVA/Starch & $\begin{array}{l}\text { Glycerol (wt\% } \\
\text { of dry weight) }\end{array}$ & $\begin{array}{l}\text { Citric acid(g) } \\
\text { (wt\% of dry } \\
\text { weight) }\end{array}$ & $\begin{array}{l}\text { CMC (wt\% of } \\
\text { dry weight) }\end{array}$ & $\begin{array}{l}\text { Walnut shell flour } \\
\text { (wt\% of dry weight) }\end{array}$ \\
\hline PSC10W2 & $3: 1$ & 20 & 5 & 10 & 2 \\
PSC10W4 & $3: 1$ & 20 & 5 & 10 & 4 \\
PSC10W6 & $3: 1$ & 20 & 5 & 10 & 6 \\
PSC10W8 & $3: 1$ & 20 & 5 & 10 & 8 \\
PSC10W10 & $3: 1$ & 20 & 5 & 10 & 10 \\
\hline
\end{tabular}




\subsection{Field emission scanning electron microscopy (FESEM) analysis}

FESEM was performed on Hitachi SU 8010 series to observe the morphology of platinum coated samples of composite films. All the samples were taken at $5 \mathrm{kV}$ power at different magnifications.

\subsection{Statistical analysis}

Films properties were measured with individually prepared films in triplicate, as the replicated results are provided with mean \pm standard deviation (SD) values. Analysis of variance (ANOVA) was performed and the significance of each mean property value was determined $(p<0.05)$.

\section{Results and discussion}

\subsection{Influence of carboxymethyl cellulose}

\subsubsection{FTIR spectroscopy}

FTIR spectra of PSC0 and PSC10, PSC20 with their characteristic peaks are shown in Fig. 1. In the spectra of PSC0, the peak obtained at $3310 \mathrm{~cm}^{-1}$ is assigned to the stretching vibration of hydroxyl groups of PVA and/or starch [32]. The peaks at 2921 and $2850 \mathrm{~cm}^{-1}$ are attributed to the asymmetric stretching of $\mathrm{C}-\mathrm{H}$ group of polymer matrix. The peak at $1724 \mathrm{~cm}^{-1}$ corresponds to the $\mathrm{C}=\mathrm{O}$ stretching vibration peak caused by the ester bond and carboxyl groups in citric acid. ${ }^{14}$ The band at $1430 \mathrm{~cm}^{-1}$ is the characteristic peak of $\mathrm{CH}_{2}$ bending with deformation. The band at $1083 \mathrm{~cm}^{-1}$ is attributed to the $\mathrm{C}-\mathrm{O}-\mathrm{H}$ bending and $\mathrm{C}-\mathrm{O}$ stretching vibration coupled with $\mathrm{O}-\mathrm{H}$ bending vibration and at $1017 \mathrm{~cm}^{-1}$ is due to the stretching of $\mathrm{C}-\mathrm{O}$ bond in $\mathrm{C}-\mathrm{O}-\mathrm{C}$ group in the anhydroglucose ring of starch [33].

In the FTIR spectra of PSC 10 and PSC20 a broad band at $3309 \mathrm{~cm}^{-1}$ corresponds to the $\mathrm{OH}$ stretching. The bands obtained at 2928 and $2835 \mathrm{~cm}^{-1}$ were due to the asymmetric stretching of $\mathrm{CH}$ groups. The peak at $1090 \mathrm{~cm}^{-1}$ arises due to the $\mathrm{C}-\mathrm{O}$ and $1030 \mathrm{~cm}^{-1}$ correspond to the $\mathrm{C}-\mathrm{O}-\mathrm{C}$ stretching of PVA backbone respectively. The peak obtained at $1728 \mathrm{~cm}^{-1}$ was attributed to the ester bond and carboxyl groups $(\mathrm{C}=\mathrm{O})$ in citric acid or due to the residual acetate groups during the manufacturing of PVA from hydrolysis reaction of polyvinyl acetate [32].

The bands at 1432 and $1260 \mathrm{~cm}^{-1}$ were assigned to the $\mathrm{CH}_{2}$ group and stretching vibration of $\mathrm{C}-\mathrm{O}$ group respectively. The existence of different individual peaks in PS composites after being modified by the addition of CMC indicates the success of blending of PVA/starch with CMC.

\subsubsection{Thermal study}

Thermogravimetric Analysis (TGA) The thermal profiles (TG and DTG) of PSC0, PSC10 and PSC20 at the heating rate of $10{ }^{\circ} \mathrm{C} \mathrm{min}^{-1}$ in an inert atmosphere of nitrogen are shown in Fig. 2.

The weight loss up to $200{ }^{\circ} \mathrm{C}$ in all the samples results from the evaporation of absorbed moisture and the volatization of easily degradable components such as glycerol [34, 35]. It was found that the PS films cross linked with citric acid (PSC0) found to show the significant thermal stability. The similar results modified by the addition of citric acid were also obtained by Zhou et al. [14] TG curves of composite (a)

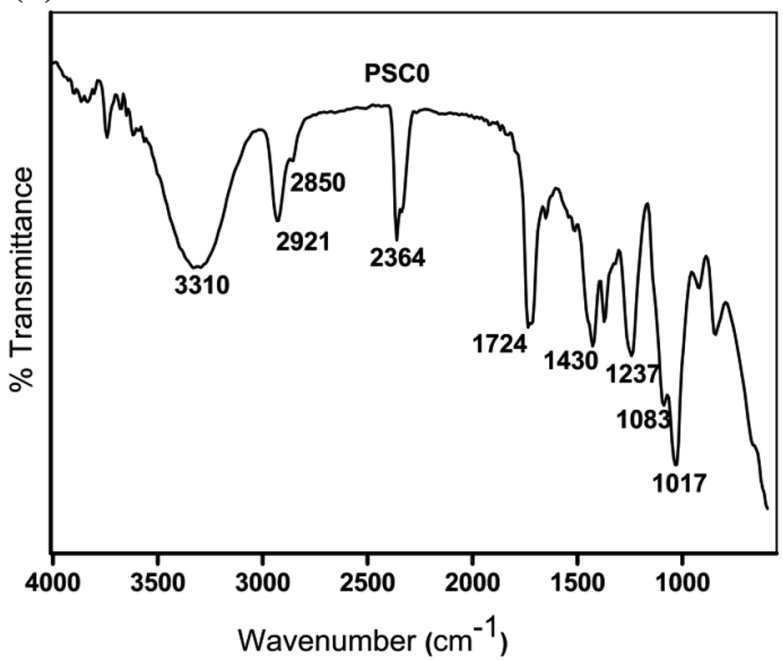

(b)

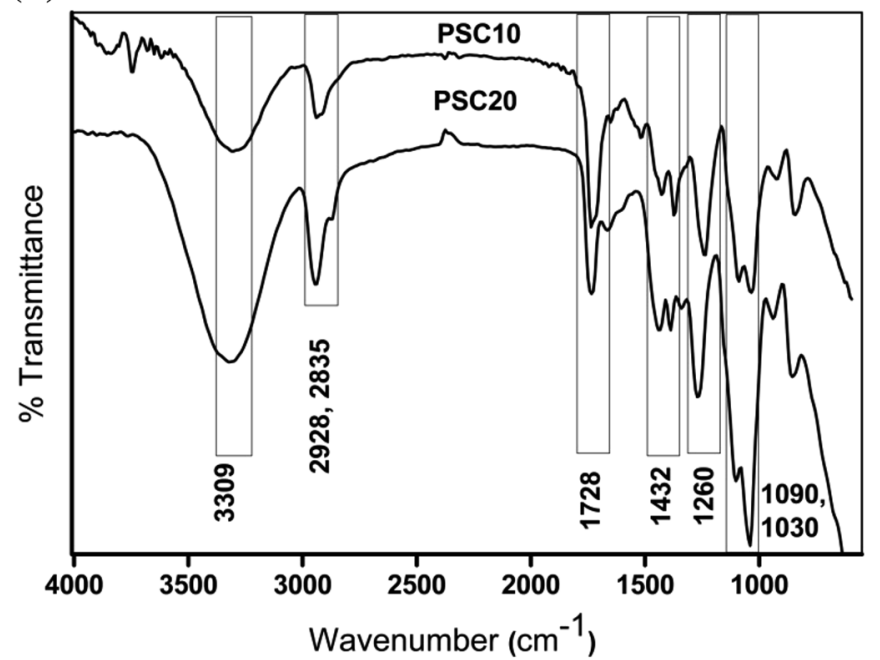

where,PSC $0=\mathrm{PVA} / \mathrm{Starch} / \mathrm{CA} / 0 \% \mathrm{CMC}, \mathrm{PSC} 10=\mathrm{PVA} / \mathrm{Starch} / \mathrm{CA} / 10 \% \mathrm{CMC}$ and $\mathrm{PSC} 20=\mathrm{PVA} / \mathrm{Starch} / \mathrm{CA} / 20 \% \mathrm{CMC}$

Fig. 1 FTIR spectra of a PSC0 and b PSC10, PSC20 
(a)

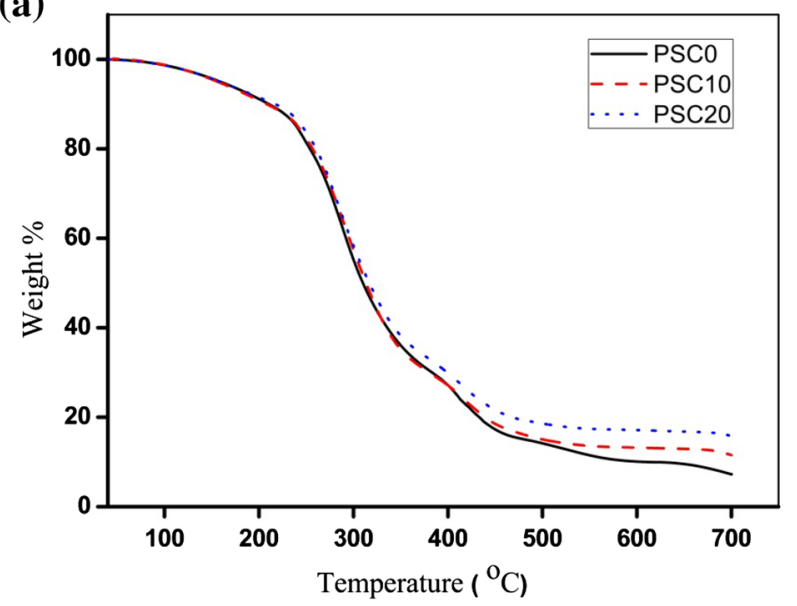

(b)

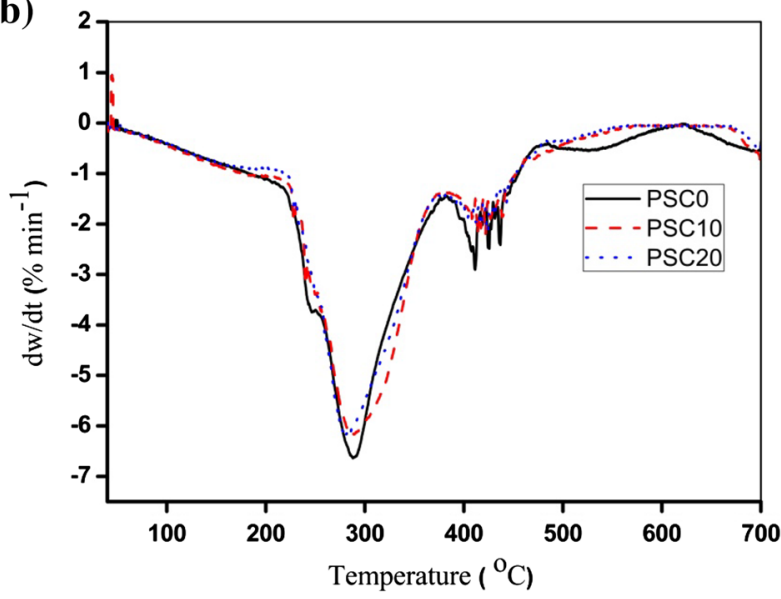

where, $\mathrm{PSC} 0=\mathrm{PVA} / \mathrm{Starch} / \mathrm{CA} / 0 \% \mathrm{CMC}, \mathrm{PSC} 10=\mathrm{PVA} /$ Starch/CA/10\%CMC and PSC20=PVA/Starch/CA/20\%CMC

Fig. 2 Thermal profiles $\mathbf{a}$ TG and $\mathbf{b}$ DTG of PSC0, PSC10 and PSC20

films showed a two step decomposition pattern. The first predominant stage of degradation from about $220-320^{\circ} \mathrm{C}$ was primarily due to the degradation of polymer chain [36, 37], followed by further weight loss in second degradation region around $360-450^{\circ} \mathrm{C}$, corresponds to the breakdown of polymer backbone [38]. There was a slight increase in the onset degradation temperature and percentage of weight residue left at $600^{\circ} \mathrm{C}$ with the addition of CMC (Table 4) in all the composite films. This is because CMC acts as a stabilizing agent [39] which provides more stability to the composite films and hence led to a decrease in percentage of weight loss which is shown in the form of increase in percentage of weight residue left with the increasing concentration of CMC. The similar trends with the addition of CMC were also observed by A.M. Shehap [40].

\subsubsection{Mechanical properties}

The ultimate tensile strength (UTS) and Young's modulus of the composite films PSC-0 to PSC- 4 are shown
Table 4 Characteristic thermal decomposition data of composite films

\begin{tabular}{llllll}
\hline $\begin{array}{lllll}\text { Sample } \\
\text { index }\end{array}$ & $\begin{array}{l}\text { Decom- } \\
\text { position } \\
\text { region }\end{array}$ & \multicolumn{3}{l}{ Temperature $\left({ }^{\circ} \mathrm{C}\right)$} & \begin{tabular}{l} 
Weight \\
residue (\%) at \\
\cline { 3 - 5 }
\end{tabular} \\
\cline { 3 - 5 } & $\mathrm{T}_{0}$ & $\mathrm{~T}_{\max }$ & $\mathrm{T}_{\text {end }}$ & $60{ }^{\circ} \mathrm{C}$ \\
\hline PSC0 & First & 222.66 & 287.24 & 333.97 & 10.07 \\
& Second & 377.57 & 411.42 & 561.55 & \\
PSC10 & First & 229.75 & 289.63 & 345.37 & 13.19 \\
& Second & 378.23 & 414.76 & 522.92 & \\
PSC20 & First & 235.54 & 280.80 & 345.72 & 17.11 \\
& Second & 380.88 & 424.49 & 514.82 & \\
\hline
\end{tabular}

in Fig. 3.The UTS of virgin polymer film (PSCO) was $19.22 \pm 0.87 \mathrm{MPa}$. The strength was found to be increased with an increase of CMC up to $10 \%$ having a value of $36.56 \pm 1.54 \mathrm{MPa}$. The reason for this increase can be due to the interfacial interaction between the polymer matrix and CMC having similar polysaccharide structure [22]. The interfacial interaction could be that the polymer matrix PVA and/or starch is able to from hydrogen bonding with the hydroxyl and carboxyl groups of CMC macromolecules and leads to the formation of strong network. The resulting structure thus resists the diffusion of water molecules in it and simultaneously improves the mechanical properties [41]. The enhancement of tensile strength of starch films with addition of CMC (till 10\%) was also observed by Ma et al. [42] Further addition of CMC from 10 to $20 \%$ led to decrease in UTS from $36.56 \pm 1.54$ to $27.73 \pm 0.32 \mathrm{MPa}$. This might be due to the aggregation of CMC in PVA/Starch matrix at high loading $(20 \%)$ as clearly shown in the FESEM images (Fig. 4c, d). Young's modulus of the composite films is also shown in Fig. 3b. The maximum value of Young's modulus was obtained in case of PSC10 ( $37.07 \pm 1.15 \mathrm{MPa})$ in comparison to the virgin film PSC0 $(32.67 \pm 0.59 \mathrm{MPa})$.

The reason for the increase of mechanical properties on the addition of CMC up to certain limit (PSC10) can be due to the fact that at further loading of hydrophilic component CMC, moisture absorption of resulting blends increases and hence deteriorates the mechanical properties. Another possible reason for this worsening can be due to the fact that in presence of CA, the effect of higher addition of CMC gets weakened. Hence, due to the limited interactions tensile strength as well as youngs modulus decreases after certain concentration of CMC. The decrease of interactions is also shown in the FESEM image of PSC20 where aggregation of CMC on one side of blend is shown (Fig. 4c, d). This is the cause that optimum results for tensile strength and youngs modulus belongs to PSC10. The similar results i.e. increasing of CMC content leading to decrease in mechanical properties were also observed by other researchers $[41,43]$. 
(a)

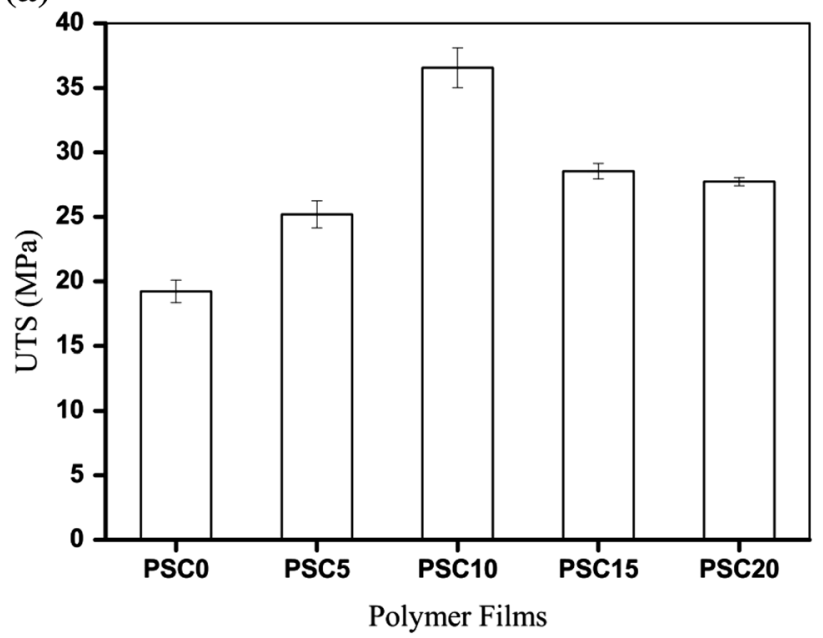

(b)

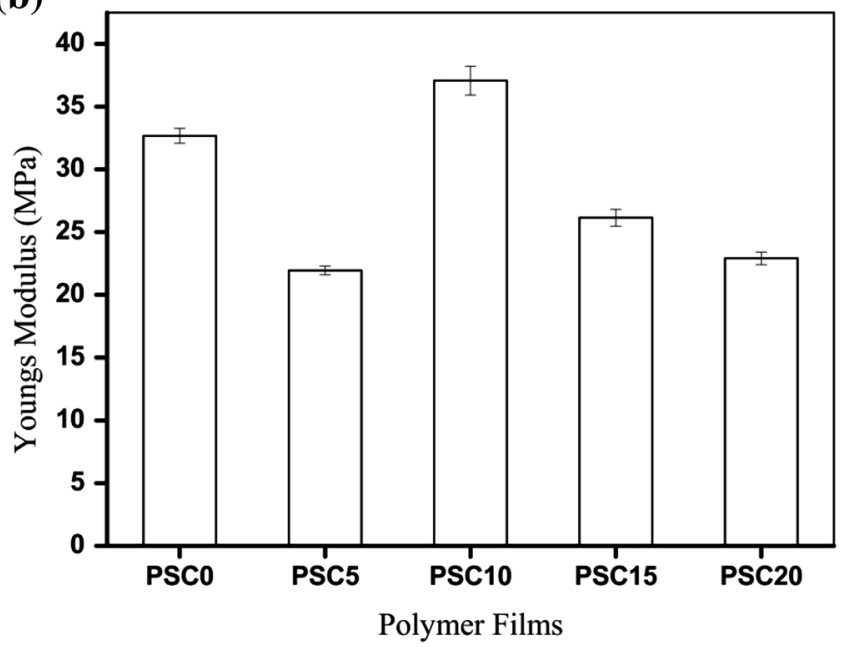

where PSC0 $=$ PVA $/$ Starch $/$ CA $/ 0 \%$ CMC, PSC5 $=$ PVA $/$ Starch $/$ CA $/ 5 \%$ CMC, PSC $10=$ PVA $/$ Starch $/$ CA $/ 10 \% \mathrm{CMC}$, $\mathrm{PSC} 15=\mathrm{PVA} / \mathrm{Starch} / \mathrm{CA} / 15 \% \mathrm{CMC}$ and PSC20 $=\mathrm{PVA} / \mathrm{Starch} / \mathrm{CA} / 20 \% \mathrm{CMC}$

Fig. 3 a Tensile strength and $\mathbf{b}$ Youngs modulus of PVA/Starch/CMC composites

(a)

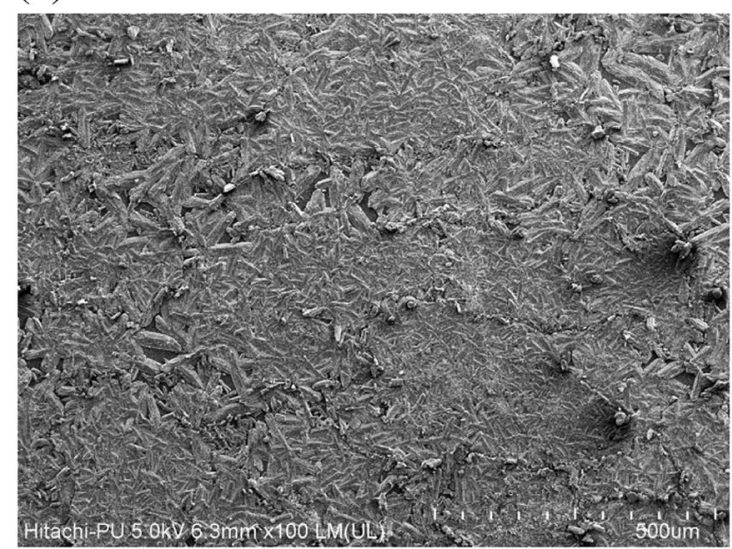

(c)

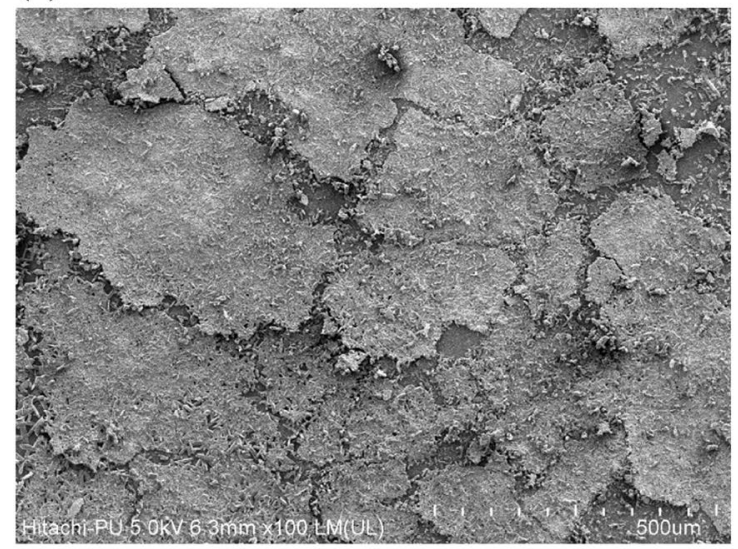

(b)

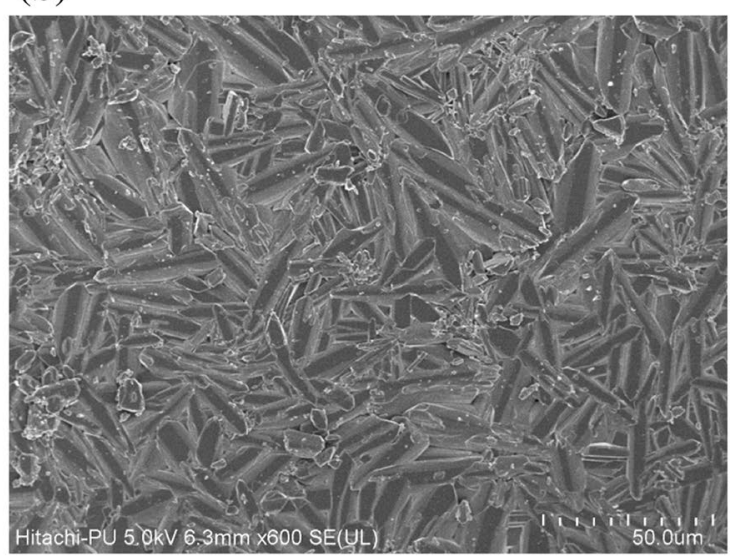

(d)

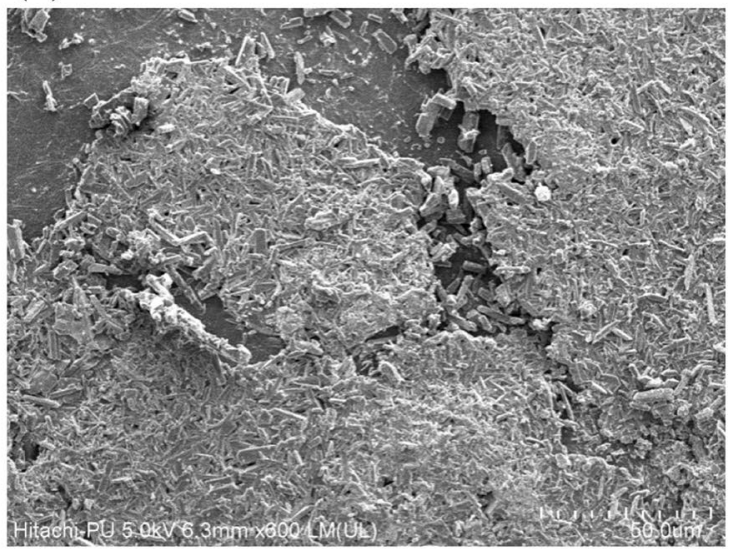

where PSC10 = PVA $/$ Starch $/$ CA $/ 10 \%$ CMC and PSC20 = PVA $/$ Starch $/$ CA $/ 20 \%$ CMC

Fig. 4 FESEM images of a PSC10 (× 100), b PSC10 (×600), c PSC20 (×100) and d PSC20 (×600 magnification) 
Table 5 One way ANOVA on tensile strength data

\begin{tabular}{lrllll}
\hline Source & DF & $\begin{array}{l}\text { Sum of } \\
\text { squares }\end{array}$ & $\begin{array}{l}\text { Mean } \\
\text { square }\end{array}$ & F-value & $p$ value \\
\hline $\begin{array}{l}\text { Composi- } \\
\text { tion }\end{array}$ & 4 & 470.8345 & 117.7086 & 124.8924 & 1.72 E-08 \\
Error & 10 & 9.4248 & 0.94248 & - & - \\
Total & 14 & 480.2593 & - & - & - \\
\hline
\end{tabular}

The statistically significant differences between mean tensile data from one sort of composition to another were verified by $p$ value $(p<0.05)$ as shown in Table 5 . The composite PSC 10 offering high tensile strength and moderate thermal stability was chosen as an optimum to analyze the effect of walnut shell flour.

\subsubsection{FESEM analyses}

The surface morphology of the PSC10 and PSC20 films is shown in Fig. 4. The surface of PSC10 film was found to be smooth and compacted. The separation of two polymer phases (PVA and starch) was not observed on $10 \%$ addition of CMC; is an evidence of uniform morphology and good compatibility between different components. The reason for observing the homogeneity in PSC films was probably due to the chemical similarities and hydrogen bonding interactions in filler and matrix. However, at further loading

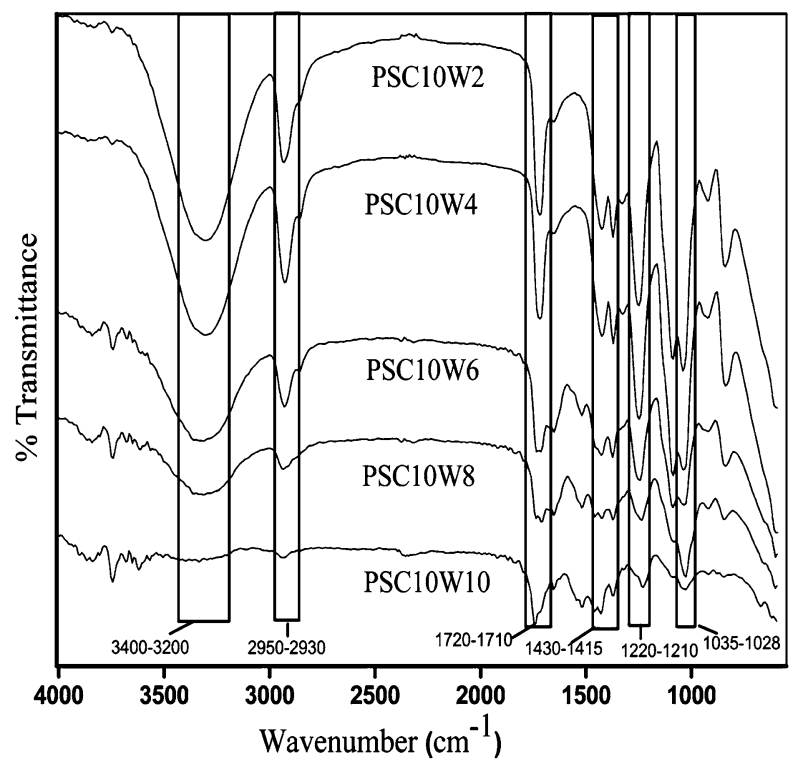

where PSC10W2 = PVA $/$ Starch $/ \mathrm{CA} / 10 \% \mathrm{CMC} / 2 \% \mathrm{WSF}$, $\mathrm{PSC} 10 \mathrm{~W} 4=\mathrm{PVA} / \mathrm{Starch} / \mathrm{CA} / 10 \% \mathrm{CMC} / 4 \% \mathrm{WSF}, \mathrm{PSC} 10 \mathrm{~W} 6=$ PVA/ Starch/ CA / $10 \% \mathrm{CMC} / 6 \% \mathrm{WSF}$, PSC10W8 = PVA/ Starch/ $\mathrm{CA} / 10 \% \mathrm{CMC} / 8 \% \mathrm{WSF}$ and PSC10W10 $=\mathrm{PVA} / \mathrm{Starch} /$ $\mathrm{CA} / 10 \% \mathrm{CMC} / 10 \% \mathrm{WSF}$

Fig. 5 FTIR spectra of composite films of CMC in PS films (PSC20), change in morphology was observed due to aggregation of CMC (Fig. 4c, d).

\subsection{Influence of walnut shell flour}

\subsubsection{FTIR spectroscopy}

The FTIR spectra of composite films from PSC10W2 to PSC10W10 are shown in Fig. 5. The characteristic peaks observed in this spectrum were almost similar to that observed in Fig. 1b. However, the intensity of peak obtained at $3400-3200 \mathrm{~cm}^{-1}$ was found to decrease continuously. The reason for the decrease in intensity of the band can be due to the fact that $\mathrm{OH}$ group is involved in hydrogen bonding with walnut flour giving rise to the polymeric association of $\mathrm{OH}$ group.
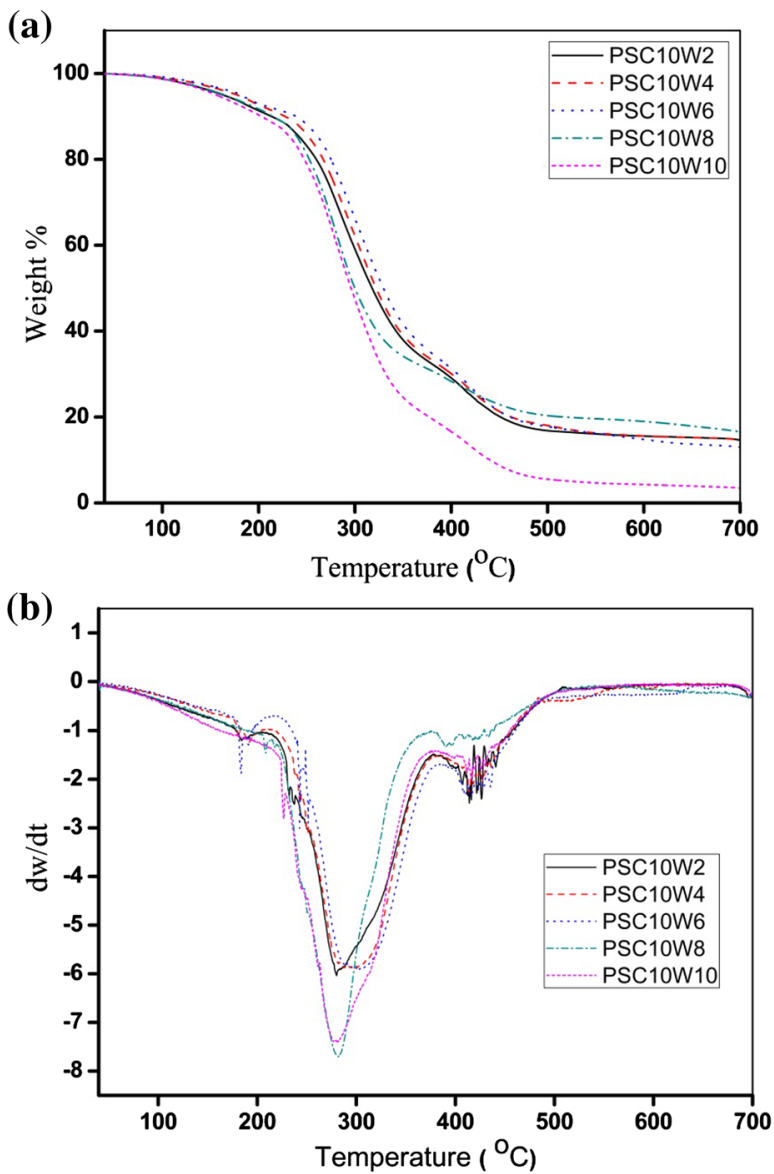

where $\mathrm{PSC} 10 \mathrm{~W} 2=\mathrm{PVA} / \mathrm{Starch} / \mathrm{CA} / 10 \% \mathrm{CMC} / 2 \% \mathrm{WSF}$, PSC10W4 $=$ PVA $/$ Starch $/$ CA $/ 10 \% \mathrm{CMC} / 4 \%$ WSF, PSC10W6 $=$ PVA/ Starch/ CA / $10 \%$ CMC/ 6\% WSF, PSC10W8 = PVA/ Starch/ $\mathrm{CA} / 10 \% \mathrm{CMC} / 8 \% \mathrm{WSF}$ and PSC10W $10=\mathrm{PVA} / \mathrm{Starch} / \mathrm{CA} / 10 \%$ $\mathrm{CMC} / 10 \% \mathrm{WSF}$

Fig. 6 Thermal profiles $\mathbf{a}$ TG and $\mathbf{b}$ DTG of different PSCW composite films 
Table 6 Characteristic thermal decomposition data of composite films

\begin{tabular}{lllll}
\hline Sample index & $\begin{array}{l}\text { Decomposi- } \\
\text { tion region }\end{array}$ & \multicolumn{3}{l}{ Temperature $\left({ }^{\circ} \mathrm{C}\right)$} \\
\cline { 3 - 5 } & & $\mathrm{T}_{0}$ & $\mathrm{~T}_{\max }$ & $\mathrm{T}_{\text {end }}$ \\
\hline PSC10W2 & First & 233.38 & 280.80 & 351.81 \\
& Second & 380.88 & 425.61 & 503.60 \\
PSC10W4 & First & 243.63 & 295.33 & 354.94 \\
& Second & 390.45 & 427.61 & 522.92 \\
PSC10W6 & First & 246.76 & 302.14 & 361.38 \\
& Second & 384.01 & 437.55 & 477.66 \\
PSC10W8 & First & 227.44 & 281.72 & 358.25 \\
& Second & 361.38 & 411.19 & 508.38 \\
PSC10W10 & First & 225.79 & 279.88 & 338.93 \\
& Second & 361.38 & 410.14 & 487.41 \\
\hline
\end{tabular}

\subsubsection{Thermal study}

Thermogravimetric Analysis (TGA) The TG curves of PSC composites reinforced with WSF are shown in Fig. 6 . It was found that principal degradation behaviour of PSCW composites has not changed with the addition of WSF in PSC composites, however shifted the TG curves to higher temperatures. This shifting is also shown in the form of increase of onset degradation temperature for PSCW composites (Table 6). The enhancement in onset degradation temperature of PSCW composites was an indication of increasing the thermal stability of composites. However, this increase was observed only up to $6 \%$ addition of flour.

Further addition led to decrease in thermal stability which can be explained in such a way that at high concentration the homogeneous dispersion of flour could not take place (Fig. 11) and nature of resulting adhesion existing between filler and matrix reduced and hence decreased the thermal stability.

\subsubsection{Mechanical properties}

It can be seen that tensile strength for PSC10W4 and PSC10W6 was nearly same with maximum value of $41.09 \pm 0.71 \mathrm{MPa}$ (Fig. 7a). Further addition of flour from 6 to $10 \%$ led to drop in tensile strength with UTS value of $31.01 \pm 0.80 \mathrm{MPa}$ for PSC10W10. The drop in tensile strength can be due to poor interfacial interaction between polymer matrix containing CMC and high concentration of shell particles. The significant change in UTS value from $35.61 \pm 0.37 \mathrm{MPa}$ (PSC10W2) (a)

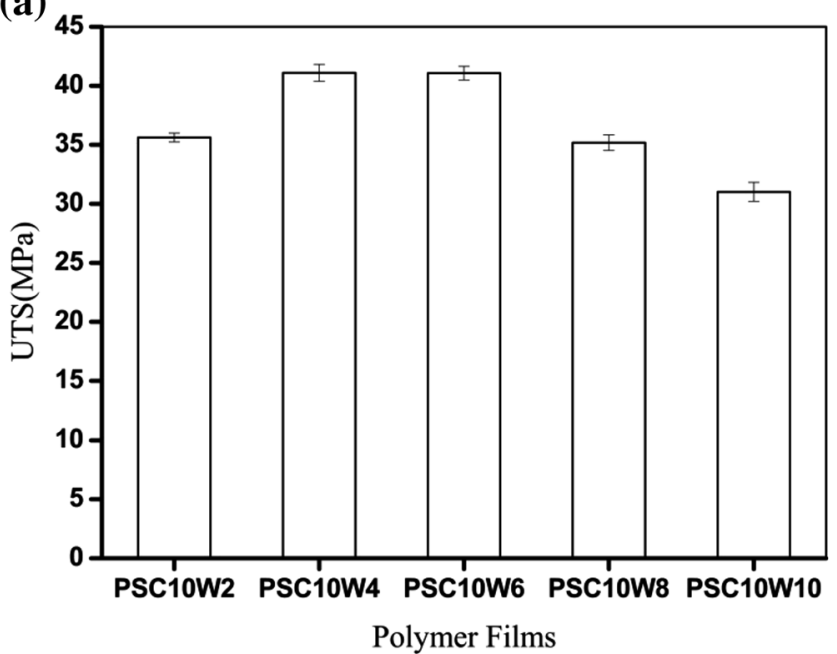

(b)

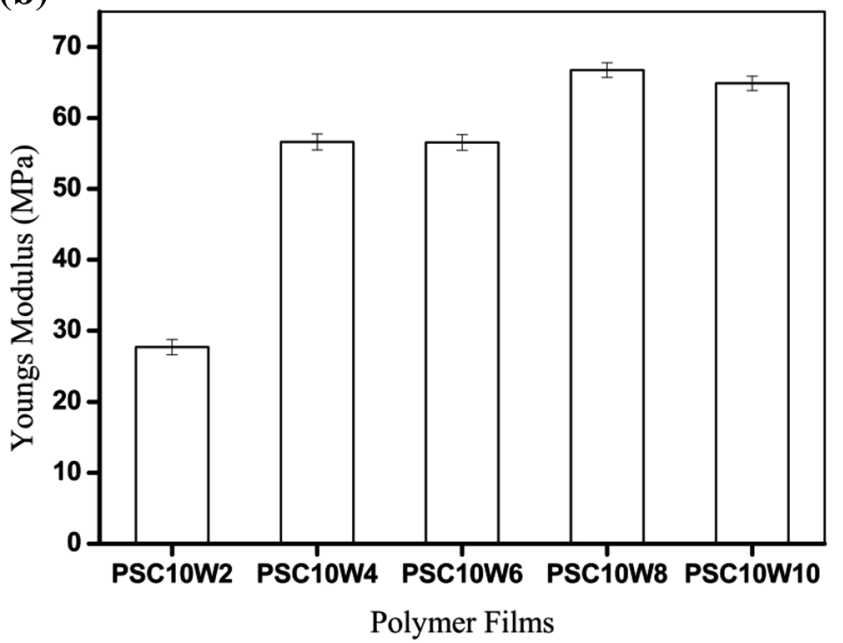

where PSC10W2 $=\mathrm{PVA} / \mathrm{Starch} / \mathrm{CA} / 10 \% \mathrm{CMC} / 2 \% \mathrm{WSF}, \mathrm{PSC} 10 \mathrm{~W} 4=\mathrm{PVA} / \mathrm{Starch} / \mathrm{CA} / 10 \% \mathrm{CMC} / 4 \% \mathrm{WSF}$, $\mathrm{PSC} 10 \mathrm{~W} 6=\mathrm{PVA} / \mathrm{Starch} / \mathrm{CA} / 10 \% \mathrm{CMC} / 6 \% \mathrm{WSF}, \mathrm{PSC} 10 \mathrm{~W} 8=\mathrm{PVA} / \mathrm{Starch} / \mathrm{CA} / 10 \% \mathrm{CMC} / 8 \% \mathrm{WSF}$ and $\mathrm{PSC} 10 \mathrm{~W} 10=\mathrm{PVA} / \mathrm{Starch} / \mathrm{CA} / 10 \% \mathrm{CMC} / 10 \% \mathrm{WSF}$

Fig. 7 a Tensile strength and b Young's modulus of composites

Table 7 One way ANOVA on tensile strength data

\begin{tabular}{lrrlll}
\hline Source & DF & Sum of squares & Mean square & F-value & $p$ value \\
\hline Composition & 4 & 222.52971 & 55.63243 & 135.75065 & $1.14267 \mathrm{E}-8$ \\
Error & 10 & 4.09813 & 0.40981 & - & - \\
Total & 14 & 226.62784 & - & - & - \\
\hline
\end{tabular}




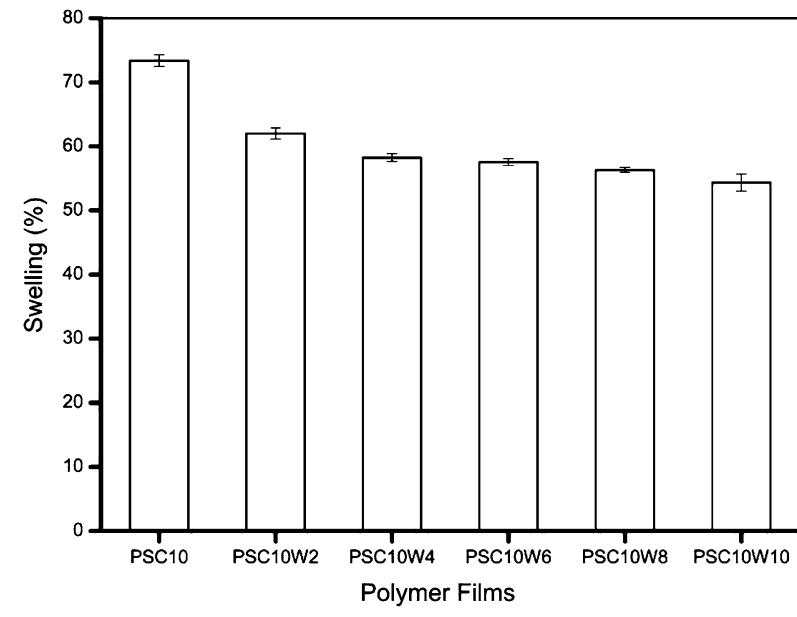

where PSC10W2 $=\mathrm{PVA} / \mathrm{Starch} / \mathrm{CA} / 10 \% \mathrm{CMC} / 2 \% \mathrm{WSF}$, $\mathrm{PSC} 10 \mathrm{~W} 4=\mathrm{PVA} / \mathrm{Starch} / \mathrm{CA} / 10 \% \mathrm{CMC} / 4 \% \mathrm{WSF}, \mathrm{PSC} 10 \mathrm{~W} 6=$ PVA/ Starch/ CA / $10 \%$ CMC/ 6\% WSF, PSC10W8 = PVA/ Starch/ $\mathrm{CA} / 10 \% \mathrm{CMC} / 8 \% \mathrm{WSF}$ and PSC $10 \mathrm{~W} 10=\mathrm{PVA} / \mathrm{Starch} / \mathrm{CA} / 10 \%$ $\mathrm{CMC} / 10 \%$ WSF

Fig. 8 Comparison of swelling percentage of different PSCW films in comparison to PSC10

to $41.09 \pm 0.71 \mathrm{MPa}$ (PSC10W6), showed that addition of flour affects the properties of matrix. The Young's modulus of composite films was also increased with maximum value of $66.74 \pm 1.04 \mathrm{MPa}$ obtained in PSC10W8. Young's modulus of the natural fiber reinforced polymer composites generally increases with increasing the fiber amount [44]. However, the low value of Young's modulus obtained for PSC10W10 can be an indication that homogeneous dispersion of flour could not take place with high flour loading. The elongation percentage was decreased continuous from 200 to $160 \%$ from PSC10W2 to PSC10W10 respectively. The statistical data of tensile strength data of PSCW films is shown in Table 7. It can be demonstrated from table that at the significant level of 0.05 there were remarkable differences between the mean percentages of tensile data from one composition to another.

\subsubsection{Swelling study}

On the addition of walnut shell flour the degree of swelling was found to decrease (Fig. 8). The DS value for PSC10 was $73.37 \pm 0.92 \%$. However, this value reached

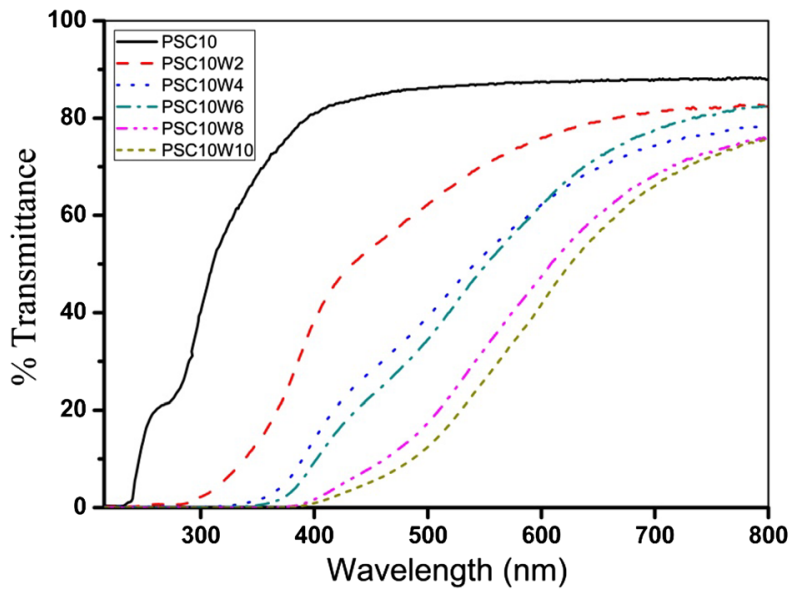

where PSC10W2 $=\mathrm{PVA} / \mathrm{Starch} / \mathrm{CA} / 10 \% \mathrm{CMC} / 2 \% \mathrm{WSF}$, $\mathrm{PSC} 10 \mathrm{~W} 4=\mathrm{PVA} / \mathrm{Starch} / \mathrm{CA} / 10 \% \mathrm{CMC} / 4 \% \mathrm{WSF}, \mathrm{PSC} 10 \mathrm{~W} 6=$ PVA/ Starch/ CA / $10 \%$ CMC/ 6\% WSF, PSC10W $8=$ PVA/ Starch/ $\mathrm{CA} / 10 \% \mathrm{CMC} / 8 \% \mathrm{WSF}$ and PSC10W10 $=\mathrm{PVA} / \mathrm{Starch} / \mathrm{CA} / 10 \%$ $\mathrm{CMC} / 10 \% \mathrm{WSF}$

Fig. 9 UV-Vis spectra of composite films

at $54.35 \pm 1.33 \%$ with $10 \%$ flour loading. A significant change of about $10 \%$ in the DS value was observed with $2 \%$ flour addition.

A further addition of flour led to continuously decrease in DS value, but the decrease was not much significant as observed with $2 \%$.

However, the overall decrease in DS value with flour addition can be due to the fact that number of free $\mathrm{OH}$ groups decreased with flour addition; as confirmed already from the decrease in intensity of $\mathrm{OH}$ group in the IR spectra of these composites (Fig. 5). A significant change in swelling percentage was also confirmed by executing one-way ANOVA $(p<0.05)$ to the data obtained as shown in Table 8.

\subsubsection{Light absorbance property}

Figure 9 shows the UV-Vis spectra of composites with different levels of walnut flour. The comparison is also made against the composite without any flour addition (PSC10). The transmittance percentage of entire composites was lower than PSC10. On increasing the amount of flour the $\%$ transmittance decreased with increasing the amount of flour. In the UV range (290-400 nm), the transmittance value
Table 8 One way ANOVA on swelling percentage data

\begin{tabular}{lrrlll}
\hline Source & DF & Sum of squares & Mean square & F-value & $p$ value \\
\hline Composition & 5 & 711.34435 & 142.26887 & 204.00599 & $3.56972 \mathrm{E}-11$ \\
Error & 12 & 8.36851 & 0.69738 & - & - \\
Total & 17 & 719.71286 & - & - & - \\
\hline
\end{tabular}




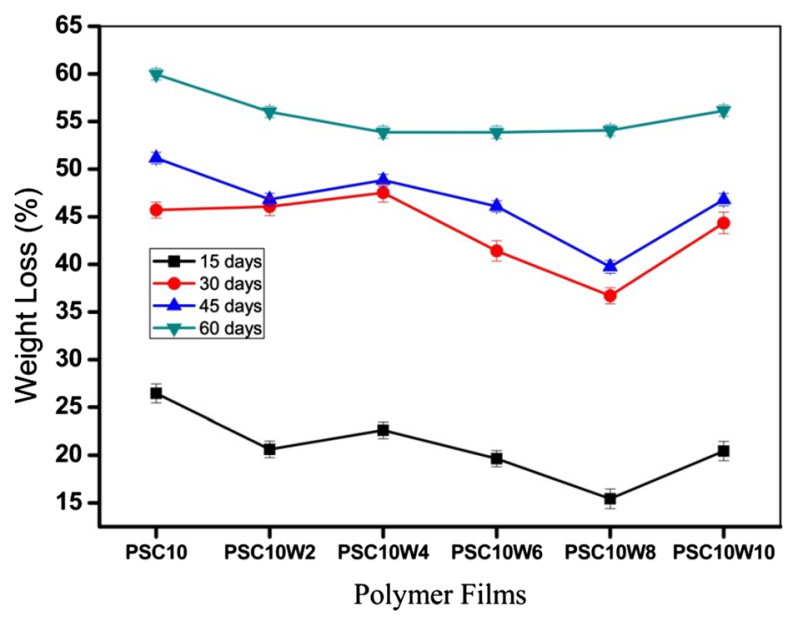

where PSC10W2 = PVA/ Starch $/ \mathrm{CA} / 10 \% \mathrm{CMC} / 2 \% \mathrm{WSF}$, $\mathrm{PSC} 10 \mathrm{~W} 4=\mathrm{PVA} / \mathrm{Starch} / \mathrm{CA} / 10 \% \mathrm{CMC} / 4 \% \mathrm{WSF}$, PSC10W6 $=$ $\mathrm{PVA} / \mathrm{Starch} / \mathrm{CA} / 10 \% \mathrm{CMC} / 6 \% \mathrm{WSF}, \mathrm{PSC} 10 \mathrm{~W} 8=\mathrm{PVA} / \mathrm{Starch} /$ $\mathrm{CA} / 10 \% \mathrm{CMC} / 8 \% \mathrm{WSF}$ and PSC10W10 = PVA/ Starch $/ \mathrm{CA} / 10 \%$ $\mathrm{CMC} / 10 \%$ WSF

Fig. 10 Plot of percentage of weight loss as a function of polymer films

(a)

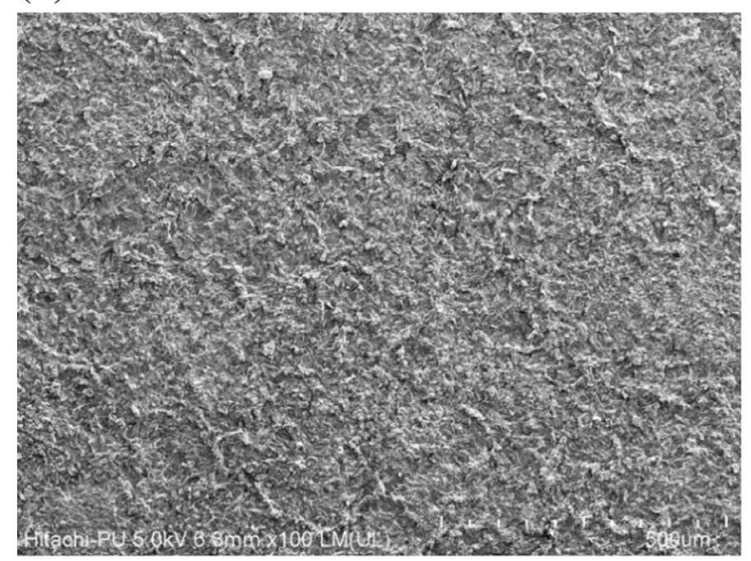

(c)

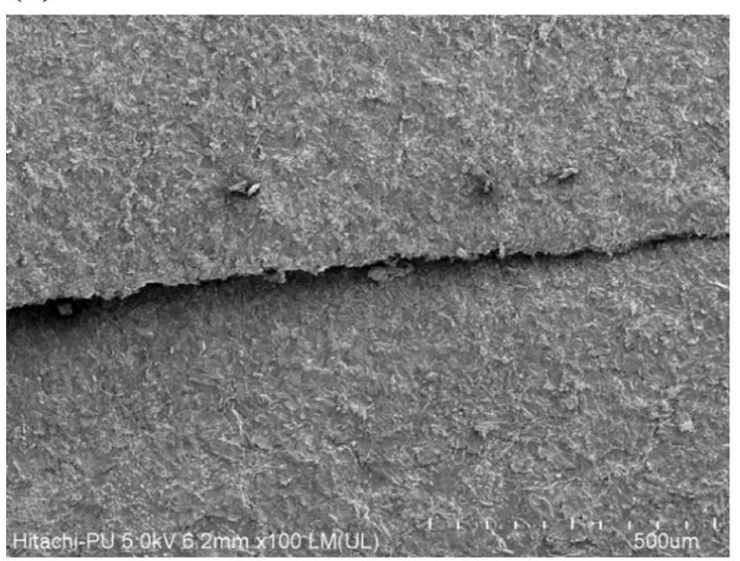

of all the composites was very low, meaning that most of the films provided shielding against UV light. As a result, these PVA/Starch/CMC films reinforced with walnut flour could potentially be used as UV-shielding materials in food and medical applications also [45].

\subsubsection{Soil degradability test}

This test was performed in order to study the biodegradability of composites by evaluating the weight loss percentage of samples due to the presence of moisture and microorganisms activity, during the time period of 90 days. All the composite samples showed the rapid degradation in time period between 15 and 30 days. PSC 10 film without any flour loading showed the maximum weight loss percentage at the end of 90 days ( $59.94 \pm 0.61)$. This might be due to the high water absorption percentage of PSC10 in comparison to the PSCW composite films as shown in Fig. 8.

Among PSCW composites, PSC10W2 and PSC10W10 showed maximum and almost equal weight loss percentage i.e. $56.0 \pm 0.59$ and $56.13 \pm 0.58$ respectively. PSC10W2

(b)

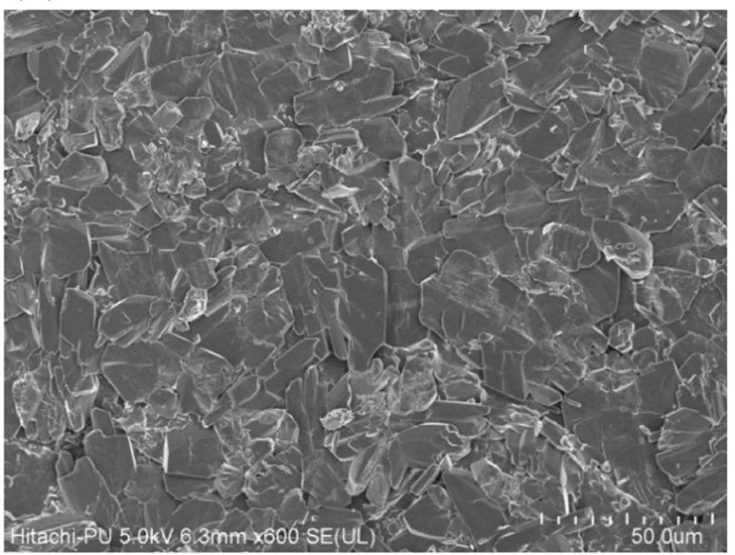

(d)

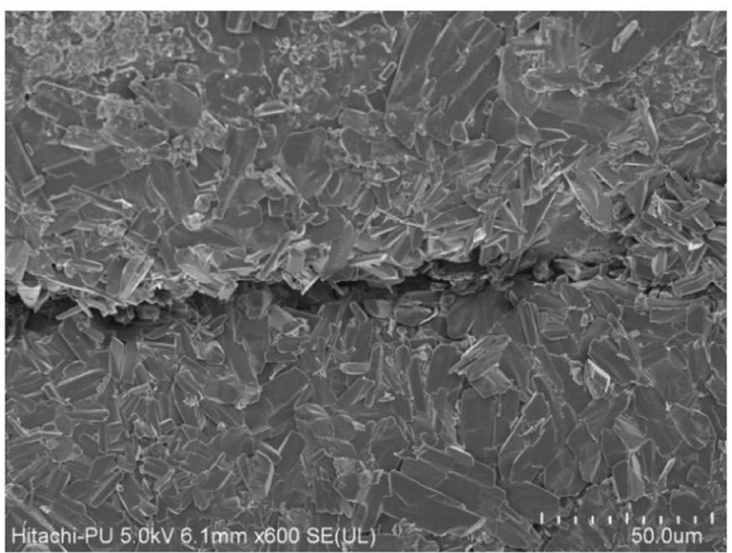

where PSC10W6 = PVA / Starch / CA / $10 \%$ CMC / 6\% WSF, PSC10W10 = PVA / Starch / CA / $10 \%$ CMC / 10\% WSF

Fig. 11 FESEM image of a PSC10W6 (×100), b PSC10W6 (×600), c PSC10W10 (×100) and d PSC10W10 (×600 magnification) 
Table 9 Two way ANOVA on soil burial degradability data

\begin{tabular}{lcclll}
\hline Source & DF & Sum of squares & Mean square & F-value & $p$ value \\
\hline $\begin{array}{l}\text { Composition } \\
\begin{array}{l}\text { Degradation time } \\
\text { period }\end{array}\end{array}$ & 5 & 1063.65706 & 212.73141 & 326.68724 & 0 \\
$\begin{array}{l}\text { Interaction } \\
\text { Model }\end{array}$ & 15 & 1764.21779 & 3454.73926 & 5305.37179 & 0 \\
Error & 23 & 11603.90713 & 504.5177 & 774.77742 & 0 \\
Total & 48 & 31.25652 & 0.65118 & - & - \\
\hline & 71 & $11,635.16365$ & - & - & - \\
\hline
\end{tabular}

due to high water absorption capacity was more susceptible to the attack of microorganisms and hence showed significant weight loss under the soil burial process (Fig. 10). However, the presence of voids, cracks and free volume in PSC10W10 as shown in FESEM image (Fig. 11c, d) made it more prone to the attack of microorganisms [46].

In addition, PSC10W4 and PSC10W6 showed the higher biodegradation resistance among all the PSCW composite samples. This might be attributed to the fact that PSC10W4 and PSC10W6 showed high cross linking and good adhesion which resist these samples to get degrade, which resulted in its high tensile strength also (Fig. 7a). As highly cross linked films shows the high degradation time period and low weight loss percentage [47]. Statistically significant differences from one level of composition to another and time of degradation on degradability data were confirmed by two-way ANOVA at the significant level of 0.05 as shown in Table 9.

\subsubsection{FESEM analyses}

The composite PSC10W6 showed homogeneous dispersion of WSF (Fig. 11a, b). However, in PSC10W10 composite containing $10 \%$ content of flour showed that homogeneity of flour was not maintained at high flour content due to the resulting poor adhesion between filler and matrix. In addition, more roughness was also observed at the higher flour content. The higher loading of walnut shell flour (PSC10W10) introduced some cracks in the films (Fig. 11c, d) which was also responsible for its high degradability under the soil burial process.

\section{Conclusions}

PVA/Starch films modified by $10 \%$ addition of CMC and offering moderate thermal stability and significant tensile strength $(36.56 \pm 1.54 \mathrm{MPa})$ value was chosen as an optimum for analyzing the effect of WSF addition. Addition of WSF improved the thermal stability and also possessed high tensile strength $(41.09 \pm 0.71 \mathrm{MPa})$. The addition of WSF led to decline in degradability percentage in comparison to composite without any WSF addition (PSC10). Also, the PSCW films were found to be more resistant towards the water absorption.

Acknowledgements Financial support from the University Grant Commission (UGC), New Delhi as Senior Research Fellowship, award letter no. 21/06/2015 (i) EU-V to Kapil Gulati is gratefully acknowledged. The author also acknowledges the Chairman, Chemistry department, Kurukshetra University, Kurukshetra for providing the necessary laboratory facilities.

\section{Compliance with ethical standards}

Conflict of interest On behalf of all authors, the corresponding author states that there is no conflict of interest.

Human and animal rights The Research work is not involving any Human Participants and/or Animals.

\section{References}

1. Vanvolkenburgh WR, White MA (1993) Overview of biodegradable polymers and solid-waste issues. Tappi J, USA

2. Scott G, Gilead D (1995) Degradable polymers in waste and litter control. Degrad Polym, Springer

3. Yang JH, Park J, Kim D, Lee D (2004) Effects of calcium carbonate as the expanding inhibitor on the structural and mechanical properties of expanded starch/polyvinyl alcohol blends. J Appl Polym Sci 93:1762-1768

4. Tang $\mathrm{S}$, Zou $\mathrm{P}$, Xiong $\mathrm{H}$, Tang $\mathrm{H}$ (2008) Effect of nano-SiO ${ }_{2}$ on the performance of starch/polyvinyl alcohol blend films. Carbohydr Polym 72:521-526

5. Westling ÅR, Stading M, Gatenholm P (2002) Crystallinity and morphology in films of starch, amylose and amylopectin blends. Biomacromolecules 3:84-91

6. Walenta E, Fink HP, Weigel P, Ganster J (2001) Structure-property relationships in extruded starch, 1 supermolecular structure of pea amylose and extruded pea amylose. Macromol Mater Eng 286:456-461

7. Averous L, Boquillon N (2004) Biocomposites based on plasticized starch: thermal and mechanical behaviours. Carbohydr Polym 56:111-122

8. Mallakpour S, Jarang N (2016) Mechanical, thermal and optical properties of nanocomposite films prepared by solution mixing 
of poly(vinyl alcohol) with titania nanoparticles modified with citric acid and vitamin C. J Plast Film Sheet 32:293-316

9. Gulati K, Lal S, Diwan PK, Arora S (2019) Investigation of thermal, mechanical, morphological and optical properties of polyvinyl alcohol films reinforced with buddha coconut (sterculia alata) leaf fiber. Int J Appl Eng Res 14:170-179

10. Zou GX, Jin PQ, Xin LZ (2008) Extruded starch/PVA composites: water resistance, thermal properties, and morphology. J Elastom Plast 40:303-316

11. Cinelli P, Chiellini E, Lawton JW, Imam SH (2006) Foamed articles based on potato starch, corn fibers and poly(vinyl alcohol). Polym Degrad Stab 91:1147-1155

12. Bin Dahman OA, Rahaman M, Khastgir D, Al-Harthi MA (2018) Electrical and dielectric properties of poly(vinyl alcohol)/starch/ graphene nanocomposites. Can J Chem Eng 96:903-911

13. Raj B, Somashekar R (2004) Structure-property relation in polyvinyl alcohol/starch composites. J Appl Polym Sci 91:630-635

14. Zhou X, Chen D, Zhang L, Tian W, Bi J, Zhu A, Shi R, Zhang Z (2008) The effect of citric acid on the structural properties and cytotoxicity of the polyvinyl alcohol/starch films when molding at high temperature. Carbohydr Polym 74:763-770

15. Park HR, Chough SH, Yun YH, Yoon SD (2005) Properties of Starch/PVA blend films containing citric acid as additive. J Polym Environ 13:375-382

16. Yin Y, Li J, Liu Y, Li Z (2005) Starch crosslinked with poly(vinyl alcohol) by boric acid. J Appl Polym Sci 96:1394-1397

17. Ramaraj B (2006) Crosslinked poly(vinyl alcohol) and starch composite films II Physicomechanical, thermal properties and swelling studies. J Appl Polym Sci 103:909-916

18. Chandra RU (1998) Biodegradable polymers. Prog Polym Sci 23:1273-1335

19. Coffin DR, Fishman ML (1993) Viscoelastic properties of pectin/ starch blends. J Agric Food Chem 41:1192-1197

20. Rachtanapun $P$, Tongdeesoontorn W, Sriburi P, Mauer LJ, Wongruong S (2011) Effect of carboxymethyl cellulose concentration on physical properties of biodegradable cassava starch-based films. Chem Cent J 5:6

21. Nie H, Liu M, Zhan F, Guo M (2004) Factors on the preparation of carboxymethylcellulose hydrogel and its degradation behavior in soil. Carbohyd Polym 58:185-189

22. Ghanbarzadeh B, Almasi $H$, Entezami AA (2011) Improving the barrier and mechanical properties of corn starch-based edible films: effect of citric acid and carboxymethyl cellulose. Ind Crops Prod 33:229-235

23. Guimarães M Jr, Botaro VR, Novack KM, Teixeira FG, Denzil Tonoli GH (2015) Starch/PVA-based nanocomposites reinforced with bamboo nanofibrils. Ind Crops Prod 70:72-83

24. Puglia D, Biagiotti J, Kenny JM (2005) A review on natural fibrebased composites-Part II: application of natural reinforcements in composite materials for automotive industry. J Nat Fibers. 1:23-65

25. Li X, Tabil LG, Panigrahi S, Crerar WJ (2006) The influence of fiber content on properties of injection molded flax fiber-HDPE biocomposites American Society of Agricultural and Biological Engineers, USA

26. Raj RG, Kokta BV, Nizio JD (1992) Studies on mechanical properties of polyethylene-organic fiber composites I Nut shell flour. J Appl Polym Sci 45:91-101

27. Buyuksari U, Ayrilmis N, Avci E, Koc E (2009) Evaluation of the physical, mechanical properties and formaldehyde emission of particleboard manufactured from waste stone pine (Pinus pinea L.) cones. Bioresour Technol 101:255-259

28. Zhao S, Niu J, Yin L, Liu K, Wang S, Wen J, Wang H, Zhang Z (2019) The relationship among the structural, cellular and physical properties of walnut shells. Hortscience 54:275-281
29. Demirbas A (2005) Bioethanol from cellulosic materials: a renewable motor fuel from biomass. Energy Source 27:327-337

30. Guru M, Atar M, Yildirim R (2006) Production of polymer matrix composite particleboard from walnut shell and improvement of its requirements. Mater Design 29:284-287

31. Ayrilmis N, Kaymakci A, Ozdemir F (2012) Physical, mechanical, and thermal properties of polypropylene composites filled with walnut shell flour. J Ind Eng Chem 19:908-914

32. Jayasekara R, Harding I, Bowater I, Christie GB, Lonergan GT (2004) Preparation, surface modification and characterisation of solution cast starch PVA blended films. Polym Test 23:17-27

33. Chen Y, Cao X, Chang PR, Huneault MA (2008) Comparative study on the films of poly(vinyl alcohol)/pea starch nanocrystals and poly(vinyl alcohol)/native pea starch. Carbohydr Polym 73:8-17

34. Taghizadeh MT, Sabouri N (2013) Thermal degradation behavior of polyvinyl alcohol/starch/carboxymethyl cellulose/clay nanocomposites. Univers J Chem 1:21-29

35. Vega D, Villar MA, Failla MD, Vallés EM (1996) Thermogravimetric analysis of starch-based biodegradable blends. Polym Bull 37:229-235

36. Holland BJ, Hay JN (2000) Thermal degradation of nylon polymers. Polym Int 49:943-948

37. Alvarez VA, Vázquez A (2004) Thermal degradation of cellulose derivatives/starch blends and sisal fibre biocomposites. Polym Degrad Stabil 84:13-21

38. Zhou XY, Jia DM, Cui YF, Xie D (2009) Kinetics analysis of thermal degradation reaction of PVA and PVA/starch blends. J Reinf Plast Comp 28:2771-2780

39. Britto DD, Assis OB (2009) Thermal degradation of carboxymethylcellulose in different salty forms. Thermochim Acta 494:115-122

40. Shehap AM (2008) Thermal and spectroscopic studies of polyvinyl alcohol/sodium carboxy methyl cellulose blends. Egypt J Solid 31:75-91

41. Ghanbarzadeh B, Almasi H, Entezami AA (2010) Physical properties of edible modified starch/carboxymethyl cellulose films. Innov Food Sci Emerg 11:697-702

42. Ma X, Chang PR, Yu J (2008) Properties of biodegradable thermoplastic pea starch/carboxymethyl cellulose and pea starch/ microcrystalline cellulose composites. Carbohydr Polym 72:369-375

43. Chetouani A, Meriem E (2014) Mahmoud b, Djaafer B. Physicochemical characterization of gelatin-cmc composite edibles films from polyion-complex hydrogels J Chil Chem Soc 59:2279-2283

44. Malkapuram R, Kumar V, Negi YS (2009) Recent development in natural fiber reinforced polypropylene composites. J Reinf Plast Comp 28:1169-1189

45. Voge CM, Johns J, Raghavan M, Morris MD, Stegemann JP (2013) Wrapping and dispersion of multiwalled carbon nanotubes improves electrical conductivity of protein-nanotube composite biomaterials. J Biomed Mater Res A 101:231-238

46. Pradhan S, Mohanty S, Nayak SK (2018) In-situ aerobic biodegradation study of epoxy-acrylate film in compost soil environment. J Polym Environ 26:1133-1144

47. Shaini VP, Jayasree S (2016) Isolation and characterization of lipase producing bacteria from windrow compost. Int J Curr Microbiol Appl Sci 5:926-933

Publisher's Note Springer Nature remains neutral with regard to jurisdictional claims in published maps and institutional affiliations. 